\title{
Use of Medicare Administrative Claims to Identify a Population at High Risk for Adverse Drug Events and Hospital Use for Quality Improvement
}

Rachel Digmann, PharmD, BCPS; Anita Thomas, PharmD; Sherry Peppercorn, BS; Amanda Ryan, PharmD, BCGP; Liling Zhang, MS; Kimberly Irby, MPH; and Jane Brock, MD, MSPH

\begin{abstract}
BACKGROUND: A system using administrative claims to monitor medication use patterns and associated adverse events is not currently available. Establishment of a standardized method to identify Medicare beneficiaries at high risk for adverse events, by assessing Medicare Part D medication claim patterns and associated outcomes, including outpatient adverse drug events (ADEs) and hospital use, enhances prevention efforts and monitoring for quality improvement efforts.
\end{abstract}

OBJECTIVES: To (a) demonstrate that Medicare claims data can be used to identify a population of beneficiaries at high risk for adverse events for quality improvement and (b) define trends associated with adverse health outcomes in identified high-risk beneficiaries for quality improvement opportunities.

METHODS: We used Medicare fee-for-service Part D claims data to identify a population at high risk for adverse events by evaluating medication use patterns. This population was taking at least 3 medications, 1 of which was an anticoagulant, an opioid, or an antidiabetic agent. Next, we used associated Part A claims to calculate rates of outpatient ADEs, looking for specific ICD-9-CM or ICD-10-CM codes in the principal diagnosis code position. Rates of hospital use (inpatient hospitalization, observation stays, emergency department visits, and 30-day rehospitalizations) were also evaluated for the identified high-risk population. The data were then shared for targeted quality improvement.

RESULTS: We identified 8,178,753 beneficiaries at high risk for adverse events, or $20.7 \%$ of the total eligible fee-for-service population (time frame of October 2016-September 2017). The overall rate of outpatient ADEs for beneficiaries at high risk was 46.28 per 1,000 , with anticoagulant users demonstrating the highest rate of ADEs $(68.52 / 1,000)$, followed by opioid users $(42.11 / 1,000)$ and diabetic medication users $(20.72 / 1,000)$. As expected, the primary setting for beneficiaries at high risk to seek care for outpatient ADEs was the emergency department, followed by inpatient hospitalizations and observation stays.

CONCLUSIONS: Medicare claims are an accessible source of data, which can be used to establish for quality improvement a population at high risk for ADEs and increased hospital use. Using medication use patterns to attribute risk and associated outcomes, such as outpatient ADEs and hospital use, is a simple process that can be readily implemented. The described method has the potential to be further validated and used as a foundation to monitor population-based quality improvement efforts for medication safety.

J Manag Care Spec Pharm. 2019;25(3):402-10

Copyright $\odot 2019$, Academy of Managed Care Pharmacy. All rights reserved.

\section{What is already known about this subject}

The 2014 National Action Plan for Adverse Drug Event Prevention identified anticoagulants, diabetes agents, and opioids as highpriority classes to focus on reducing adverse drug events (ADEs). Medication safety efforts are limited by the lack of a national system to measure medication use patterns and associated health outcomes, such as ADEs and hospital use, for quality improvement efforts.

Measurement of outpatient ADEs is difficult, and no standard method for evaluation is currently available.

\section{What this study adds}

This study describes a method, using Medicare claims data, to identify a population of fee-for-service Medicare beneficiaries at high risk for adverse events and hospital use based on nonhospital medication use patterns.

Use of Medicare claims data to establish a population of high-risk Medicare beneficiaries and track associated ADE rates provides a much needed public surveillance resource that can support medication management improvement efforts.

The high-risk Medicare beneficiary population had an annual ADE rate of 46.28 per 1,000 and used all hospital services at significantly higher rates compared with Medicare beneficiaries who were not high risk.

A dverse drug events (ADEs) are common among older persons; however, information on outpatient ADEs is lacking. In 2003, Gurwitz et al. reported that ADEs are common among ambulatory geriatric patients, with an overall rate of ambulatory ADEs in a Medicare population of 50.1 per 1,000 person-years. ${ }^{1}$ Older adults are especially vulnerable, as age-related physiologic changes, coexisting conditions, and polypharmacy increases the risk of an ADE and the health impact of experiencing one. ${ }^{2,3}$ Reducing ADEs is a priority focus of the quality improvement strategy of the Centers for Medicare \& Medicaid Services (CMS). ${ }^{4}$

The Department of Health and Human Services (HHS) released the National Action Plan for Adverse Drug Event Prevention (ADE Action Plan) in 2014 identifying 
anticoagulants, opioids, and diabetes agents as high-priority drug class targets for ADE prevention efforts. ${ }^{5}$ One fundamental challenge for organizing national efforts to prevent ADEs, noted in the report, is the lack of a public health surveillance system that measures outpatient ADE rates and reports in a timely fashion. A system for evaluating population medication use in combination with ADE rates could not only track changes in ADE rates but also provide real-time insight on whether improvements in outpatient ADE rates are based on safety improvements or changes in medication use patterns.

The report also notes the complex array of factors contributing to ADEs that are important considerations for prevention strategies, including polypharmacy and associated patient misuse of medications. These risks are particularly relevant to Medicare beneficiaries. Not only are they frequently exposed to polypharmacy, but the pool of medications present in their homes is also likely to far exceed their active medication lists as a result of modifications in medication regimens. The probably common but unmeasured extent and prevalence of this reality underscores the complexity of $\mathrm{ADE}$ prevention beyond the simpler situation implied by single specific exposure leading to a defined event. ${ }^{3}$

A decade ago, Budnitz et al. (2007) proposed applying principles of injury epidemiology to ADE reduction efforts by identifying potentially modifiable pre-event "host" characteristics and developing prevention efforts aimed at preoccurrence factors. ${ }^{6}$ CMS is using this conceptual strategy in the Quality Innovation Network-Quality Improvement Organization (QIN-QIO) program's 11th Scope of Work by identifying a subset of the fee-for-service (FFS) Medicare population at higher than usual risk for ADE through multiple medication exposures over the interval of a year. ${ }^{4}$ QIN-QIOs are charged with supporting ADE prevention through collaborative efforts to improve medication management processes across the care continuum.

CMS initiated the work by defining "high risk" as use of at least 3 medications, 1 of which is a medication from 1 of the priority classes. ${ }^{1,3,4}$ The aim was to define a population subset large enough that improvement would have meaningful implications for the Medicare program yet focused enough to represent a population more than averagely exposed to risk of ADE. To measure ADE rates, we built on the work of others by choosing hospital care as a marker for prehospital gaps in medication management and developed a set of International Classification of Diseases, Ninth Revision, Clinical Modification (ICD-9-CM) and International Classification of Diseases, Tenth Revision, Clinical Modification (ICD-10-CM) codes per priority drug class that feasibly represent ADEs' given exposure. ${ }^{7-12}$ We calculated outpatient ADE rates per year for the beneficiary population at high risk and priority class-specific ADE rates by using the appropriate codes per exposure group. We compared all-cause hospital use rates among the population identified as high risk with the population not identified as high risk.
Our approach is substantially different from traditional ADE measurement because our methods do not temporally couple known exposure to ADEs. Our approach monitored a population known to be in a high-risk temporally defined window for occurrence of ADE-compatible hospital care events (emergency department [ED] visits, observation stays, and inpatient hospitalizations) occurring during the same window. Our purpose was to enable claims data to serve as a population health-monitoring source for tracking mediation use patterns, health outcomes, ADE rates, and improvement in those rates associated with multistakeholder collaborative improvement activities.

\section{Methods}

We used Medicare fee-for-service (FFS) claims data available to the QIN-QIO program, including Part A (inpatient, observation stay, and ED) and Part D prescription drug claims. We limited the dataset for these analyses to FFS beneficiaries covered under the Medicare Prescription Drug Plan. FFS enrollment and eligibility were obtained from the Medicare Denominator File. All analyses were based on the most recent Medicare claims data covering a 12-month time period (October 2016-September 2017). The work reported in this study represents CMS quality improvement contract work that is part of health care operations so was exempt from institutional review board review.

\section{Defining a Population of Medicare Beneficiaries at High Risk} Part D claims use the National Drug Code (NDC), a drug description system developed and maintained by the U.S. Food and Drug Administration (FDA). ${ }^{13}$ Because the NDC does not include a drug class categorization, we created a list of medications for each priority drug class list in the ADE Action Plan (anticoagulants, opioids, and diabetes medications) by proprietary and nonproprietary medication names. ${ }^{5}$ All identified names were matched to the FDA NDC file (first accessed January 2016) to create NDC number lists for each drug class, including any NDC (active and inactive) that contained a drug name on the initial list as a component (NDC numbers are available from the authors upon request). ${ }^{13}$

We merged the final NDC list with 12 months of Part D claims (October 2016-September 2017) by nonproprietary drug name, categorizing exposure as 30-59 days or 60 days or more. We maintained the definition of a "beneficiary at high risk," as provided by CMS in the QIN-QIO 1lth scope of work, and assigned high-risk status to any FFS Medicare beneficiary using at least 3 prescriptions for 60 or more nonconsecutive days, plus a high-priority medication for 30 or more nonconsecutive days or any Medicare FFS beneficiary receiving at least 2 prescription medications for 60 or more nonconsecutive days, plus 1 priority medication for 60 nonconsecutive days within a calendar year. ${ }^{4}$ 


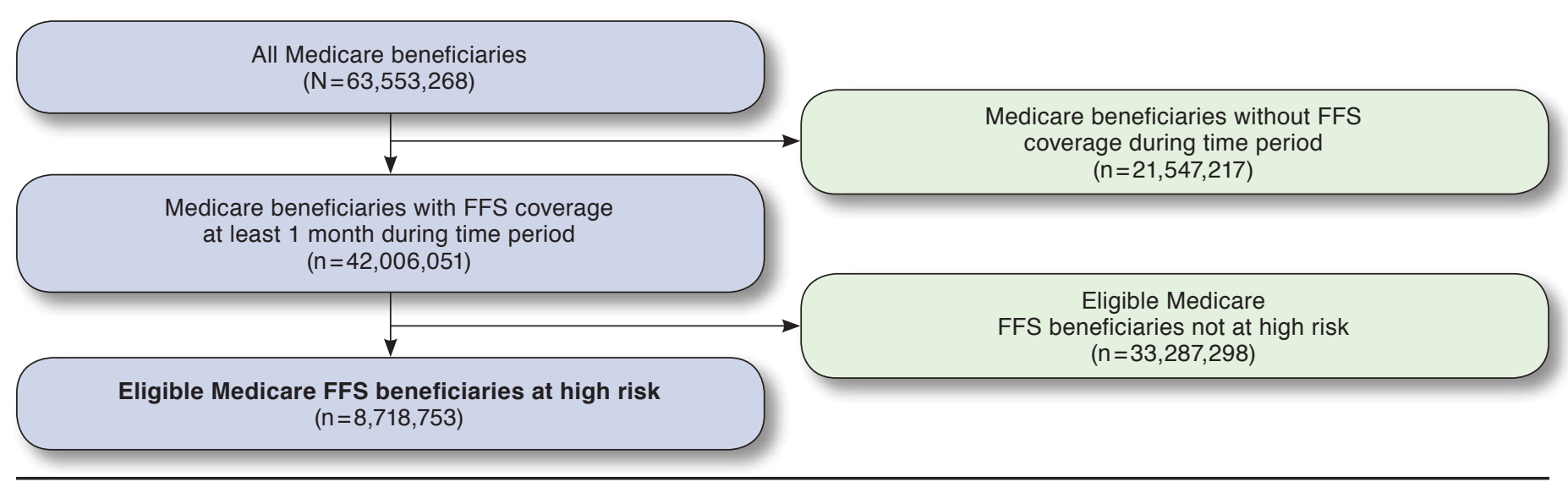

Based on Medicare claims data from October 2016 to September 2017.

FFS = fee for service.

\section{Outcomes}

Outpatient ADEs. We started with a list of ICD-9-CM/ICD10-CM codes, from previously published work, to identify codes reasonably associated with ADEs by priority drug class (Appendix A, available in online article). ${ }^{8-10}$ Additional codes were added to the initial list based on descriptions that reasonably represent priority drug class outpatient ADEs. We convened a technical advisory panel (Appendix B, available in online article) of pharmacists, physicians, and medical coding experts to review the list of proposed outpatient ADE diagnosis codes for beneficiaries exposed to an anticoagulant, an opioid, or a diabetes medication. Three virtual meetings in early 2015 supported discussion and refinement of ADE code lists per drug class exposure. We cross-walked the final list of ADE ICD-9-CM codes to associated ICD-10-CM codes using general equivalence mappings to generate a list of codes that would be useful across the entire QIN-QIO 5-year contract cycle. ${ }^{14,15}$

We merged the list of Medicare identification numbers for all beneficiaries in the high-risk population with Part A claims and identified hospital care events for each beneficiary from October 2016 to September 2017 using national claims history $(\mathrm{NCH})$ claim type, revenue center code, and Healthcare Common Procedure Coding System (HCPCS) code variables. We counted sequential levels of hospital service at the highest service level (i.e., we excluded any ED visit immediately preceding an observation stay and any observation stay immediately preceding an inpatient hospitalization claim). Any admission to a short-term acute care hospital, critical access hospital, psychiatric hospital, or psychiatric unit qualified as a hospitalization. We excluded long-term care facilities, rehabilitation hospitals and units, and children's hospitals. Any hospitalization occurring within 24 hours of admission to a different hospital was considered a transfer, which we counted as a single event.

Each principal diagnosis code for each hospital care event was compared with the list of ICD-9/10-CM codes designating outpatient ADEs. Beneficiaries flagged for exposure to more than 1 priority drug class were assessed for each set of relevant ADE codes. Occurrences of hospital care indicating possible ADEs were tallied per beneficiary. We expressed overall outpatient ADEs as rates per beneficiary-year, by calculating total number of ADEs divided by total beneficiary days, using the Medicare enrollment file to calculate days of FFS eligibility per beneficiary at high risk. Drug class-specific rates were calculated across all beneficiaries exposed to the drug class.

We did not risk adjust outpatient ADE rates, as our goal was to calculate an outpatient ADE rate for the entire population identified by medication use patterns, not to assess the independent risk conferred by the medication use pattern.

Hospital Use (All Cause). We linked the file of beneficiaries at high risk to Part A claims to determine all-cause hospital use. We defined all-cause hospital use as the sum of all hospital care events for each beneficiary from October 2016 through September 2017, using NCH claim type, revenue center code, and HCPCS code variables. We did not stratify for any particular diagnosis. As previously mentioned, we counted sequential levels of hospital service at the highest service level. Any hospitalization in a short-term acute-care hospital, critical-access hospital, psychiatric hospital, or psychiatric unit qualified as a hospitalization. We excluded long-term care facilities, rehabilitation hospitals and units, and children's hospitals. Any hospitalization occurring within 24 hours of a hospitalization at a different hospital was considered a transfer, which we counted as a single hospitalization. 


\begin{tabular}{|c|c|c|}
\hline $\begin{array}{l}\text { De } \\
\text { Me } \\
\text { Ver }\end{array}$ & $\begin{array}{l}\text { graphic Chara } \\
\text { are Beneficiari } \\
\text { s Beneficiaries }\end{array}$ & $\begin{array}{l}\text { ristics of } \\
\text { at High Risk } \\
\text { t at High Risk }\end{array}$ \\
\hline \multirow[b]{2}{*}{ Characteristics } & $\begin{array}{c}\text { FFS Medicare } \\
\text { Beneficiaries at } \\
\text { High Risk } \\
(\mathbf{n}=8,718,753)\end{array}$ & $\begin{array}{c}\text { FFS Medicare } \\
\text { Beneficiaries } \\
\text { Not at High Risk } \\
(\mathbf{n}=33,287,298)\end{array}$ \\
\hline & n (\%) & n (\%) \\
\hline \multicolumn{3}{|l|}{ Age group, years } \\
\hline$<65$ & $1,817,113 \quad(20.8)$ & $5,087,962 \quad(15.3)$ \\
\hline $65-69$ & $1,746,656 \quad(20.0)$ & $10,355,806 \quad(31.1)$ \\
\hline $70-74$ & $1,699,553 \quad(19.5)$ & $6,794,137 \quad(20.4)$ \\
\hline $75-79$ & $1,363,133 \quad(15.6)$ & $4,310,324 \quad(12.9)$ \\
\hline $80-84$ & $993,983 \quad(11.4)$ & $2,967,080 \quad(8.9)$ \\
\hline $85+$ & $1,098,315 \quad(12.6)$ & $3,771,989 \quad(11.3)$ \\
\hline \multicolumn{3}{|l|}{ Gender } \\
\hline Male & $3,825,726 \quad(43.9)$ & $15,784,706 \quad(47.4)$ \\
\hline Female & $4,893,027 \quad(56.1)$ & $17,502,592 \quad(52.6)$ \\
\hline \multicolumn{3}{|l|}{ Race } \\
\hline White & $6,565,860 \quad(75.3)$ & $25,762,647 \quad(77.4)$ \\
\hline Black & $1,024,569 \quad(11.8)$ & $3,205,701 \quad(9.6)$ \\
\hline Hispanic & $644,253 \quad(7.4)$ & $2,106,424 \quad(6.3)$ \\
\hline Asian & $257,661 \quad(3.0)$ & $904,405 \quad(2.7)$ \\
\hline North American Native & $56,768 \quad(0.7)$ & $181,977 \quad(0.5)$ \\
\hline Other/unknown & $169,642 \quad(1.9)$ & $1,126,144 \quad(3.4)$ \\
\hline \multicolumn{3}{|l|}{ Dual Eligible } \\
\hline Nondual & $5,778,844 \quad(66.3)$ & $28,618,261 \quad(86.0)$ \\
\hline Dual & $2,939,909 \quad(33.7)$ & $4,669,037 \quad(14.0)$ \\
\hline \multicolumn{3}{|l|}{ Rural } \\
\hline Nonrural & $5,622,999 \quad(64.5)$ & $23,062,656 \quad(69.3)$ \\
\hline Rural & $3,095,754 \quad(35.5)$ & $10,224,642 \quad(30.7)$ \\
\hline
\end{tabular}

We expressed hospital use as rates per beneficiary-year, using the Medicare enrollment file to calculate days of FFS eligibility per beneficiary at high risk. To compare hospital use in the high-risk population with use in the population not at high risk, we dichotomized use as "yes" for at least 1 hospital care event and "no" for none. We used multivariate logistic regression using SAS 9.1 (SAS Institute, Cary, NC) in a Unix environment to adjust for demographic factors.

\section{Results}

Our definition of high risk, based on medication use patterns and exposure to priority drug class medications, identified $20.7 \%(n=8,718,753)$ of the total eligible Medicare FFS population $(\mathrm{N}=42,006,051)$ as beneficiaries at high risk (Figure 1). More than half of the high-risk population were female (56.1\%), and a majority were younger than aged 75 years $(60.3 \%)$. Beneficiaries at high risk were primarily white (75.3\%), not dual eligible (66.3\%), and did not live in ZIP codes designated as rural (64.5\%) by the U.S. Census Bureau definition of a urbanized area (Table 1). ${ }^{4}$
All demographic variables tested showed statistically significant differences between beneficiaries at high risk and those not at high risk, as could be expected in testing a dataset of more than 40 million observations.

The overall outpatient ADE rate in the beneficiary population at high risk was 46.28 per 1,000 FFS beneficiaries at high risk. By priority drug class exposure, anticoagulant users had the highest rate of outpatient ADEs at 68.52 per 1,000, followed by opioids users at 42.11 per 1,000 and users of diabetes agents with 20.72 per 1,000 (Figure 2 and Table 2). As expected, the ED is the most frequently used hospital setting for outpatient ADE treatment, followed by inpatient hospitalizations and observation stays.

After adjustment for age, gender, race, dual eligibility status and rural residence, the beneficiary population at high risk had higher risk for overall hospital use (odds ratio $[\mathrm{OR}]=2.34,95 \%$ confidence interval $[\mathrm{CI}]=2.34-2.35, P<0.0001)$ compared with beneficiaries not at high risk (Table 3).

\section{Discussion}

The definition of beneficiaries at high risk accounts for the dual risks of multiple medication use and exposure to the high-priority medications targeted by the ADE Action Plan..$^{5}$ It can also support ADE reduction efforts through describing a subgroup in which event detection is more likely and more effective, ensuring that improvement activities focus on those most likely to benefit. ${ }^{11}$ The subset of the Medicare FFS population identified by our high-risk criteria is at increased risk for all types of hospital use, including hospitalization, ED visits, and observation stays. It is especially true for beneficiaries on multiple medications and using an anticoagulant. Although anticoagulant users are the smallest proportion of the high-risk population, they have the highest rates of hospital use and the highest rates of ADEs (Table 2).

To validate the association between the medication use characteristics we used to define our high-risk population and hospital use, we performed a simple logistic regression comparing use in the high-risk population with the population not included in the high-risk category, adjusting for common demographic factors (Table 3). The population at high risk had 2.34 times higher risk of hospital use than those not at high risk (95\% CI $=2.35-2.35, P<0.0001)$, and high-risk status was more strongly associated with hospital use than gender, race, dual eligibility, or rural residence. The only factor more strongly associated with hospital use was advanced age, with those aged 80 years or older having the highest risk.

The selection of 3 or more medications as a criterion for elevated risk in the elderly aligns with previous research and provides a metric of risk easily remembered by clinicians and patients. ${ }^{4,7}$ Use of annual days supply to determine medication exposure and adherence is established in the literature and is easily tracked through Medicare Part D data. ${ }^{16}$ Monitoring a high-risk population over time provides a population-based, 


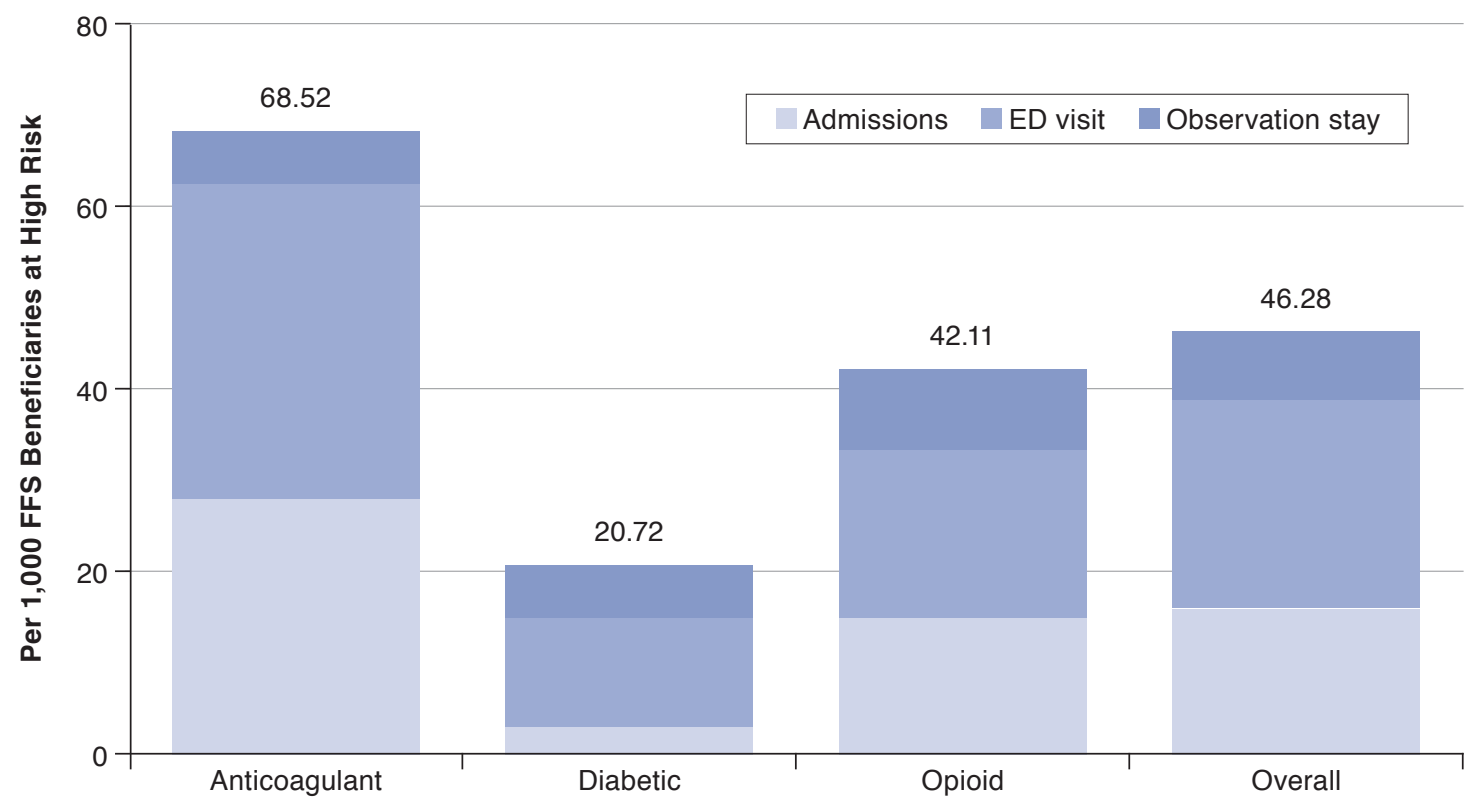

$A D E=$ adverse drug event; $E D=$ emergency department; FFS = fee for service.

claims-based approach for analyzing trends in medication use patterns, and health outcomes that are not tied to specific types of medical services. It identifies risk outside of institutional care, laying the foundation for managing the challenge of safe medication use as a community problem that requires cooperative work among an array of providers. The striking differences in proportion of the total FFS Medicare population included in the highrisk population per state (range: $12.6 \%-28.7 \%$; average: $20.6 \%$ ) also suggests a wide degree of localized variation in medication use practices, which might be used to illuminate best practices for reducing ADE occurrence through improved prescribing.

Our finding of an overall outpatient ADE rate of 46.28 per 1,000 beneficiaries at high risk is similar to a previous report by Gurwitz et al. (2003; 50.1 ambulatory ADEs/1,000 personyears) and Gabriel et al. (2017; 21-44/1,000 Medicare diabetes beneficiaries). ${ }^{1,11}$ However, our numbers may still represent a conservative estimate for a high-risk population. We calculated our rates using only principal diagnosis codes or the coding reflecting the "condition established after study to be chiefly responsible for occasioning the admission of the patient to the hospital for care." ${ }^{14,15}$ Our count, therefore, limited detection to events not only severe enough to require hospital care but also to the subset of those that were the principal cause of the hospital contact. We believe this conservative approach minimized the capture of hospital-related ADEs and supports our intention to estimate the prevalence of events related to nonhospital medication management.
We undertook this work to define a population in which rates would be high through known risks and that can be monitored using only administrative (claims) data. It is not a replacement for other more rigorous surveillance efforts but is intended to supplement them with an available, easily produced measurement strategy that can be used to track change produced by improvement efforts enacted in local health care markets without burdening medical providers. The Centers for Disease Control and Prevention's National Electronic Injury Surveillance System-Cooperative Adverse Drug Events Surveillance System (NEISS-CADES) measures outpatient ADE by detailed clinical record review and sampling of ED visits and emergent hospitalizations attributed to harm from outpatient drug use. ${ }^{17}$ NEISS-CADES participation is time and effort intensive, requiring a dedicated data collection coordinator. To be counted as an ADE, the clinical documentation must include specific notation of drug exposure and the timing of that exposure. Resulting national estimates are calculated from a set of representative hospitals. The Agency for Healthcare Research and Quality's Healthcare Cost and Utilization Project (HCUP) uses administrative claims and ICD-9/10-CM codes like our method, but they do not report an outpatient ADE rate..$^{18,19}$ Rather, they rely on voluntary participation of hospitals, leading to variation among states in degree of participation and data elements submitted among those choosing to participate. Neither NEISS-CADES nor HCUP can estimate the size of the population using high-risk medications, account for risks 
Use of Medicare Administrative Claims to Identify a Population

at High Risk for Adverse Drug Events and Hospital Use for Quality Improvement

TABLE 2 Outpatient ADEs and Hospital Use for Beneficiaries at High Risk by Priority Drug Class

\begin{tabular}{|c|c|c|c|c|c|c|c|}
\hline \multirow[b]{2}{*}{ Measures } & \multirow[b]{2}{*}{ Setting } & \multicolumn{2}{|c|}{ Anticoagulant $(n=2,262,523)$} & \multicolumn{2}{|c|}{ Diabetic $(n=4,823,414)$} & \multicolumn{2}{|c|}{ Opioid $(\mathrm{n}=3,877,876)$} \\
\hline & & $\mathrm{n}$ & $\begin{array}{l}\text { Per } 1,000 \\
\text { FFS BHRs }\end{array}$ & $\mathrm{n}$ & $\begin{array}{l}\text { Per } 1,000 \\
\text { FFS BHRs }\end{array}$ & $\mathrm{n}$ & $\begin{array}{l}\text { Per } 1,000 \\
\text { FFS BHRs }\end{array}$ \\
\hline \multirow{4}{*}{$\begin{array}{l}\text { Adverse drug } \\
\text { events }\end{array}$} & ED visits & 79,312 & 35.05 & 55,513 & 11.51 & 73,284 & 18.90 \\
\hline & OBS stays & 12,352 & 5.46 & 28,854 & 5.98 & 32,342 & 8.34 \\
\hline & Inpatient hospitalizations & 63,357 & 28.00 & 15,588 & 3.23 & 57,681 & 14.87 \\
\hline & Total ADEs & 155,021 & 68.52 & 99,955 & 20.72 & 163,307 & 42.11 \\
\hline \multirow{4}{*}{$\begin{array}{l}\text { Hospital } \\
\text { use }\end{array}$} & ED visits & $1,712,188$ & 756.76 & $2,966,547$ & 615.03 & $3,993,915$ & $1,029.92$ \\
\hline & OBS stays & 324,709 & 143.52 & 460,116 & 95.39 & 543,511 & 140.16 \\
\hline & Inpatient hospitalizations & $1,809,426$ & 799.74 & $2,207,583$ & 457.68 & $2,740,260$ & 706.64 \\
\hline & Total hospital use & $3,846,323$ & $1,700.01$ & $5,634,246$ & $1,168.10$ & $7,277,686$ & $1,876.72$ \\
\hline
\end{tabular}

Based on Medicare FFS claims from October 2016 to September 2017.

$A D E=$ adverse drug event; $B H R=$ beneficiary at high risk; $E D=$ emergency department; $F F S=$ fee for service; OBS = observation .

associated with multiple medication use, associate medication use patterns with health outcomes, nor track medication use patterns over time.

This method for ADE measurement is not intended, and is not appropriate, for performance measurement applied to individual providers. Although we tested the independent association of high-risk status with hospital use outcomes, we did so to verify that our population definition and ADE measurement strategy were reasonable for use in tracking medication management quality and that the association of high-risk status with important outcomes were not due to demographic confounders. In our quality improvement initiatives, we do not use this metric as a risk-adjusted measure. We also do not recommend complete reliance on this measurement strategy as a substitute for provider-collected internal data in assessing the gains made by individual provider-specific efforts.

\section{Limitations}

Although the methods described are a good foundational start, there remain important limitations. First, most of the ICD9/10-CM codes used for these analyses were not designed for the purpose of conducting ADE surveillance and do not reflect linkage of harms to medication use. Diagnostic codes that are designed to identify adverse events attributable to a drug (i.e., External Causes of Injury Codes [E-codes]) are included in the set of codes we used, but as in other research, they represent a small fraction of identified codes and have been found to lack sensitivity for capturing ADEs. ${ }^{20}$ Because we used the codes in association with a population defined by exposure, sensitivity should be enhanced, but coding practices often reflect local and variable norms, making ICD codes an imperfect data source for determination of outcomes. Additionally, we may have omitted relevant codes, causing us to miss hospitalizations that should be considered ADE related. Future quality improvement initiatives should include a focus on assisting providers in better using the ICD-10-CM codes designed to capture ADEs and/or building the capacity of coding systems to capture nuances related to possible medication related events.

Second, the current method calculates prevalence of events per year in a population known to be high risk each year but does not temporally tie exposure with event. Much of the previous research on ADEs seeks to establish "causation" of an event based on timing of exposure to specific medications. Our method is similar to public health surveillance, which is "the ongoing, continuous collection, analysis and interpretation of data, closely integrated with the timely dissemination of these data to those responsible for preventing and controlling disease and injury."21 A fundamental principle of public health surveillance is that surveillance should be designed and implemented to provide information in a timely manner at the lowest possible cost. ${ }^{21}$ Sacrificing precision-in this case timing of medication fills related to adverse events- makes sense to improve timeliness of data dissemination and save resources that can be used for interventions.

The notion that ADEs only occur within a specified timeframe associated with medication fill dates fails to consider that patient medication fills do not necessarily equal medication exposure. Often patients will have numerous medications and various doses available at home with easy access to use. Although claims data provide a medication fill date, we do not know when ingestion of that medication occurs, nor do we know the effect of retained medication in the home. Consideration of timing of priority medication fills via Part D claims and event timing in Part A claims may provide more precise and actionable information for health care improvement activities in the future but may ultimately delay the ability to disseminate information in a timely fashion. Our main purpose, however, was to enable claims data to serve as a public health monitoring source for tracking medication use patterns, health outcomes, ADE rates, and improvement in those rates associated with multistakeholder collaborative improvement activities via the QIN-QIO program. 


\begin{tabular}{|c|c|}
\hline Characteristic & Odds Ratio (95\% CI) \\
\hline \multicolumn{2}{|l|}{ ADE risk status } \\
\hline Beneficiaries at high risk & $2.34 \quad(2.34-2.35)$ \\
\hline Beneficiaries not at high risk & $1.00^{\mathrm{a}}$ \\
\hline \multicolumn{2}{|l|}{ Age group, years } \\
\hline$<65$ & $1.91 \quad(1.90-1.91)$ \\
\hline $65-69$ & $1.00^{\mathrm{a}}$ \\
\hline $70-74$ & $1.45 \quad(1.45-1.46)$ \\
\hline $75-79$ & $1.91 \quad(1.90-1.91)$ \\
\hline $80-84$ & $2.48 \quad(2.48-2.49)$ \\
\hline $85+$ & $3.39 \quad(3.38-3.40)$ \\
\hline \multicolumn{2}{|l|}{ Gender } \\
\hline Female & 1.09 ( $1.09-1.09)$ \\
\hline Male & $1.00^{\mathrm{a}}$ \\
\hline \multicolumn{2}{|l|}{ Race } \\
\hline White & $1.00^{\mathrm{a}}$ \\
\hline Black & $1.13 \quad(1.12-1.13)$ \\
\hline Hispanic & $0.79 \quad(0.79-0.79)$ \\
\hline Asian & $0.48 \quad(0.48-0.48)$ \\
\hline North American Native & $1.06 \quad(1.05-1.07)$ \\
\hline Other/unknown & $0.62 \quad(0.61-0.62)$ \\
\hline \multicolumn{2}{|l|}{ Dual eligibility status } \\
\hline Dual eligible & $1.84(1.83-1.84)$ \\
\hline Nondual eligible & $1.00^{\mathrm{a}}$ \\
\hline \multicolumn{2}{|l|}{ Geographic location } \\
\hline Rural & $1.13 \quad(1.12-1.13)$ \\
\hline Nonrural & $1.00^{\mathrm{a}}$ \\
\hline \multicolumn{2}{|c|}{$\begin{array}{l}\text { Based on Medicare claims from October } 2016 \text { to September } 2017 . \\
\text { aReference group. } \\
\text { ADE=adverse drug event; CI = confidence interval. }\end{array}$} \\
\hline
\end{tabular}

\section{Conclusions}

Our method is an effective way to use claims data to identify a FFS Medicare population at high risk for ADEs, which is likely to be useful in tracking improvement in ADE rates generated through comprehensive approaches to improving medication management generally. We estimate that 46.29 per 1,000 beneficiaries at high risk experience an ADE within a 12-month exposure period. These methods allow tracking and trending of ADE rates and population medication use patterns, which addresses the lack of a public health surveillance process, an important limitation of national safety work that aims to reduce ADEs. The identified population has double to triple the rate of events compared with the overall FFS population. Data generated using an administrative claims-based process to identify a high-risk population can guide timely quality improvement efforts to improve medication management. Additionally, this method lays the foundation for establishing national public health surveillance of outpatient ADE rates and associated health outcomes by priority drug classes.

\section{Authors}

RACHEL DIGMANN, PharmD, BCPS, Telligen, Des Moines, Iowa. ANITA THOMAS, PharmD, Centers for Medicare \& Medicaid Services, Baltimore, Maryland, and AMANDA RYAN, PharmD, BCGP, Qsource, Memphis, Tennessee. SHERRY PEPPERCORN, BS; LIJING ZHANG, MS; KIMBERLY IRBY, MPH; and JANE BROCK, MD, MSPH, Telligen, Greenwood Village, Colorado.

AUTHOR CORRESPONDENCE: Rachel Digmann, PharmD, BCPS, Clinical Pharmacy Specialist, Telligen, 1776 W. Lakes Pkwy., West Des Moines, IA 50266. Tel.: 515.273.8876;

E-mail: rdigmann@telligen.com.

\section{DISCLOSURES}

This work was performed under contract HHSM-500-2014-QINNCC, Modification No. 000004, funded by Centers for Medicare \& Medicaid Services (CMS), an agency of the U.S. Department of Health and Human Services. CMS did not have a role in the analysis. At the time of this analysis, Digmann, Peppercorn, Zhang, Irby, and Brock were employees of Telligen, which was awarded the National Coordinating Center-Quality Improvement Organization contract from CMS, which supported the work. Ryan was an employee at Qsource, which was awarded the Quality Innovation NetworkQuality Improvement Organization contract from CMS, which supported the work. Thomas was employed by CMS. The content is solely the responsibility of the authors and does not necessarily represent the official views or policies of the CMS. This work is posted on the QIOprogram.org website, as recommended in the Common Rule (https://www.hhs.gov/ohrp/regulations-andpolicy/regulations/common-rule/index.html).

\section{ACKNOWLEDGMENTS}

This project depended on the coordinated efforts of several participants in the government, the QIN-QIOs, and the community. The writing team is grateful to Jim Turpin with TMF (formerly); Darren Triller, PharmD, with IPRO (formerly); and Kyle Campbell, PharmD, with HSAG, who provided guidance in the initial construction of the ADE ICD code lists based on experience from previous work. Also, thanks to Beth Stevens, with Telligen, for analytic guidance and support. The Quality Innovation Network National Coordinating Center (QIN NCC) and CMS are grateful to the entire Technical Advisory Panel for their insight and feedback on the development and finalization of the ADE ICD code lists. The medication safety work depended critically on these leaders and their expertise, which was provided without compensation.

\section{REFERENCES}

1. Gurwitz J, Field T, Harrold L. Incidence and preventability of adverse drug events among older persons in the ambulatory setting. JAMA. 2003;289(9):1107-16.

2. Salvi F, Marchetti A, D’Angelo F, Boemi M, Lattanzio F, Cherubini A Adverse drug events as a cause of hospitalization in older adults. Drug Saf. 2012;35(Suppl 1):29-45.

3. Medicare Payment Advisory Committee. Chapter 5: Polypharmacy and opioid use among Medicare Part D enrollees. In: Relationship between polypharmacy, adherence, and patient confusion: report to the Congress: Medicare and the health care delivery system. June 2015. Available at: http://medpac.gov/ docs/default-source/reports/june-2015-report-to-the-congress-medicare-andthe-health-care-delivery-system.pdf. Accessed January 22, 2019. 
4. Centers for Medicare \& Medicaid Services. Quality Innovation Network (QIN) Quality Improvement Organizations (QIOs). QIN-QIO 1lth Statement of Work awards. 2014. Available at: https://www.fbo.gov/?s=opportunity\&m ode $=$ form $\&$ id $=9$ a679a5 cbe7f3a8b5098e6a366939852 \&tab=core\&_cview $=1$. Accessed January 22, 2019.

5. U.S. Department of Health and Human Services. National action plan for adverse drug event prevention. 2014. Available at: https://health.gov/hcq/ pdfs/ade-action-plan-508c.pdf. Accessed January 22, 2019.

6. Budnitz D, Layde P. Outpatient drug safety: new steps in an old direction. Pharmacoepidemiol Drug Saf. 2007;16(2):160-65.

7. Bourgeois FT, Shannon MW, Valim C, Mandl KD. Adverse drug events in the outpatient setting: an 11-year national analysis. Pharmacoepidemiol Drug Saf. 2010;19(9):901-10

8. Ginde AA, Blanc PG, Lieberman RM, Camargo CA Jr. Validation of ICD9-CM coding algorithm for improved identification of hypoglycemia visits. BMC Endocr Disord. 2008;8:4.

9. Budnitz DS, Lovegrove MC, Shehab N, Richards CL. Emergency hospitalizations for adverse drug events in older Americans. N Engl J Med. 2011;365(21):2002-12

10. Shehab N, Sperling LS, Kegler SR, Budnitz DS. National estimates of emergency department visits for hemorrhage-related adverse events from clopidogrel plus aspirin and from warfarin. Arch Intern Med. 2010;170(21):1926-33

11. Gabriel M, Powers C, Encinosa W, Bynum J. E-prescribing and adverse drug events: an observational study of the Medicare Part D population with diabetes. Med Care. 2017;55(5):456-62.

12. Braden JB, Russo J, Fan MY, et al. Emergency department visits among recipients of chronic opioid therapy. Arch Intern Med. 2010;170(16):1425-32.

13. U.S. Food \& Drug Administration. National Drug Code directory. December 11, 2018. Available at: https://www.fda.gov/Drugs/ InformationOnDrugs/ucm 142438.htm. Accessed January 22, 2019.
14. Centers for Disease Control and Prevention. ICD-10-CM official guidelines for coding and reporting. 2014. Available at: https://www.cdc.gov/nchs/ data/icd/icd10cm_guidelines_2014.pdf. Accessed January 22, 2019.

15. Centers for Medicare \& Medicaid Services. ICD-10-CM official guidelines for coding and reporting. 2016. Available at: https:/www.cms.gov/ Medicare/Coding/ICD10/Downloads/2016-ICD-10-CM-Guidelines.pdf. Accessed January 22, 2019

16. Taitel M, Fensterheim L, Kirkham H, Sekula R, Duncan I. Medication days' supply, adherence, wastage, and cost among chronic patients in Medicaid. Medicare Medicaid Res Rev. 2012;2(3):pii: mmrr.002.03.a04.

17. Office of Disease Prevention and Health Promotion. National electronic injury surveillance system-cooperative adverse drug event surveillance project. January 19, 2019. Available at: https://www.healthypeople.gov/2020/ data-source/national-electronic-injury-surveillance-system-cooperativeadverse-drug-event. Accessed January 22, 2019.

18. Agency for Healthcare Research and Quality. Healthcare Cost and Utilization Project (HCUP). January 2019. Available at: https://www.hcupus.ahrq.gov/. Accessed January 22, 2019.

19. Weiss A, Bailey M, O'Malley L, Barrett M, Elixhauser, Steiner C. Patient characteristics of opioid-related inpatient stays and emergency department visits nationally and by state, 2014. HCUP Statistical Brief \#224. June 2017. Available at: https://www.hcup-us.ahrq.gov/reports/statbriefs/sb224-PatientCharacteristics-Opioid-Hospital-Stays-ED-Visits-by-State.pdf. Accessed January 22, 2019.

20. Leonard CE, Haynes K, Localio AR, et al. Diagnostic E-codes for commonly used, narrow therapeutic index medications poorly predict adverse drug events. J Clin Epidemiol. 2008;61(6):561-71.

21. Nsubuga P, White M, Thacker S, et. al. Public health surveillance: a tool for targeting and monitoring interventions. In: Jamison DR, Breman JG, Measham AR, et al, eds. Disease Control Priorities in Developing Countries. 2nd ed. New York: Oxford University Press; 2006:997-1016. 
Use of Medicare Administrative Claims to Identify a Population

at High Risk for Adverse Drug Events and Hospital Use for Quality Improvement

APPENDIX A High-Priority Drug Class ICD-9/10-CM Codes Indicative of an Adverse Drug Event

\begin{tabular}{|c|c|}
\hline $\begin{array}{l}\text { Anticoagulant } \\
\text { (ICD-9-CM) }\end{array}$ & $\begin{array}{l}\text { E9804, E9342, E8582, 9642, 79092, 78639, 78630, 7848, 7847, 7827, 71919, 71918, 71917, 71916, 71915, 71914, 71913, } 71912, \\
71911,71910,6271,59971,59970,5789,5781,5780,5693,56881,53551,53541,53541,53521,53511,53511,53461,53460, \\
53441,53440,53421,53420,53401,53400,53361,53360,53341,53340,53321,53320,53301,53300,53261,53260,53241, \\
53240,53221,53220,53201,53200,53161,53160,53141,53140,53121,53120,53101,53100,53082,53021,4590,4558,4552, \\
4551,4329,4321,4320,431,430,4230,37923,37632,37272,36281,2859,2851,2800\end{array}$ \\
\hline $\begin{array}{l}\text { Anticoagulant } \\
\text { (ICD-10-CM) }\end{array}$ & $\begin{array}{l}\text { T45525S, T45525D, T45525A, T45524S, T45524D, T45524A, T45521S, T45521D, T45521A, T45515S, T45515D, T45515A, T45514S, } \\
\text { T45514D, T45514A, T45511S, T45511D, T45511A, R791, R58, R319, R310, R233, R049, R0489, R042, R041, R040, N950, M2508, } \\
\text { M25076, M25075, M25074, M25073, M25072, M25071, M25069, M25062, M25061, M25059, M25052, M25051, M25049, } \\
\text { M25042, M25041, M25039, M25032, M25031, M25029, M25022, M25021, M25019, M25012, M25011, M2500, K922, K921, } \\
\text { K920, K661, K648, K625, K2991, K2971, K2961, K2951, K2941, K2931, K286, K284, K282, K280, K276, K274, K272, K270, } \\
\text { K266, K264, K262, K260, K256, K254, K252, K250, K228, K2211, I629, I621, I6203, I6202, I6201, I6200, I619, I618, I616, I615, } \\
\text { I614, I613, I612, I611, I610, I609, I608, I607, I606, I6052, I6051, I6050, I604, I6032, I6031, I6030, I6022, I6021, I6020, I6012, } \\
\text { I6011, I6010, I6002, I6001, I6000, I312, H4313, H4312, H4311, H4310, H3563, H3562, H3561, H3560, H1133, H1132, H1131, } \\
\text { H1130, H05239, H05233, H05232, H05231, D649, D62, D500 }\end{array}$ \\
\hline $\begin{array}{l}\text { Diabetic } \\
\text { (ICD-9-CM) }\end{array}$ & 2511, 2512, 7802, 78097, 9623, 99523, E8588, E9323, E9804 \\
\hline $\begin{array}{l}\text { Diabetic } \\
\text { (ICD-10-CM) }\end{array}$ & $\begin{array}{l}\text { E08649, El60, E161, E162, R410, R4182, R55, T383X1A, T383X1D, T383X1S, T383X4A, T383X4D, T383X4S, T383X5A, } \\
\text { T383X5D, T383X5S }\end{array}$ \\
\hline $\begin{array}{l}\text { Opioid } \\
\text { (ICD-9-CM) }\end{array}$ & $\begin{array}{l}\text { E9804, E9800, E9620, E9352, E9351, E8502, E8501, 96509, 96502, 7991, 79902, 79901, 78097, 7802, 7801, 78009, 78003, } \\
\text { 78002, 78001, 51882, 51881, 51851, 30553, 30552, 30551, 30400, 2929, 29289, 29289, 29285, 29284, 29281, 2922, } 29212, \\
\text { 29211, } 2920\end{array}$ \\
\hline $\begin{array}{l}\text { Opioid } \\
\text { (ICD-10-CM) }\end{array}$ & 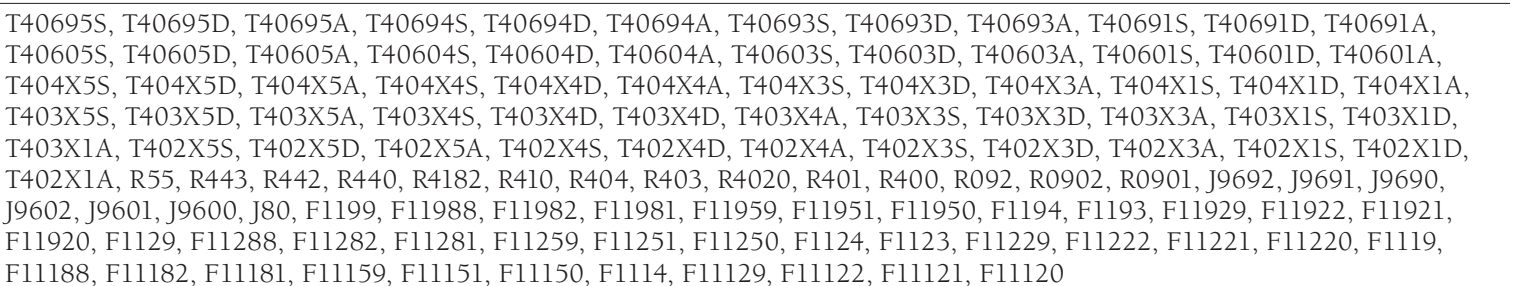 \\
\hline
\end{tabular}

ICD-9-CM = International Classification of Diseases, Ninth Revision, Clinical Modification; ICD-10-CM = International Classification of Diseases, Tenth Revision,

Clinical Modification.

\begin{tabular}{l}
\hline APPENDIX B $\begin{array}{l}\text { List of Technical Advisory Panel } \\
\text { Members }\end{array}$ \\
\hline Rosa Baier, Brown University \\
Dr. Dale Hu, CMS HHS \\
Dr. Rob Schreiber, Hebrew Senior Life/Harvard \\
Julie Kuhle, PQA \\
Brian Isetts, University of Minnesota \\
Deborah Perfetto, AHRQ \\
Andy Romero HealthInsight \\
Nelly Leon, AHA \\
Keela Herr, University of Iowa \\
Nadine Shehab, CDC \\
\hline
\end{tabular}

